\title{
Serum Osteocalcin and Bone and Liver Alkaline Phosphatase Isoforms in Healthy Children and Adolescents
}

\author{
PER MAGNUSSON, ANDERS HÄGER, AND LASSE LARSSON \\ Bone and Mineral Metabolic Unit, Department of Clinical Chemistry [P.M., L.L.] and \\ Department of Pediatrics [A.H.], Linköping University Hospital, S-581 85 Linköping, Sweden
}

\section{ABSTRACT}

We report reference values for osteocalcin and bone and liver alkaline phosphatase (ALP) isoforms in serum from 114 healthy children and adolescents, age 7-16 y. The bone and liver ALP isoforms were measured by high performance liquid chromatography (HPLC). Six ALP isoforms were separated and quantified in all samples: one bone/intestinal (B/I), two bone (B1 and B2), and three liver ALP isoforms (L1, L2, and L3). It is especially important to make distinctions between ages and gender during puberty in the interpretation of biochemical markers of bone. We observed that girls reached adult levels for osteocalcin, total ALP, and bone ALP isoforms, B/I, B1, and B2, earlier than boys. Girls in the oldest age group (15-16 y) and in the pubertal stage groups IV-V, reached higher levels than boys for the calculated ratio $\mathrm{B} 1 / \mathrm{B} 2$ due to a more rapid decline of $\mathrm{B} 2$ compared with $\mathrm{B} 1$.
This observation might indicate that $\mathrm{B} 2$, to a higher extent than the $\mathrm{B} 1$ isoform, represent a more mature expression of osteoblast differentiation during matrix mineralization in growing bone. Serial measurements of these new bone ALP isoforms could provide new insights into bone and mineral metabolism. (Pediatr Res 38: 955-961, 1995)

Abbreviations
ALP, alkaline phosphatase [orthophosphoric-monoester
phosphohydrolase (alkaline optimum)]; EC 3.1.3.1
B/I, bone/intestinal alkaline phosphatase
B1 and B1, bone 1 and 2 alkaline phosphatases
L1, L2, and L3, liver 1, 2, and 3 alkaline phosphatases
HPLC, high performance liquid chromatography

ALP is one of the most thoroughly investigated enzymes in the routine clinical chemistry laboratory and the most frequently used biochemical marker for osteoblastic bone formation. At least four human gene loci are encoding for the ALP isoenzymes; "tissue nonspecific," placental, germ cell, and small intestinal locus (1). ALP from the tissue nonspecific locus is expressed in tissues such as bone, liver, and kidney. Different carbohydrate side chains or maybe remaining fragments of the in situ cell membrane glycosyl-phosphatidylinositol anchor, or both, yields "tissue-specific" structures in the ALP isoforms from this gene locus (2). In concordance with strict isoenzyme definition (3), bone and liver ALP should be referred to as isoforms of the same isoenzyme.

Osteocalcin (bone-Gla protein) is a bone matrix protein of 49 amino acid residues (molecular mass 5800 D) containing three calcium binding $\gamma$-carboxyglutamic acids which is mainly synthesized in bone by osteoblasts. Only a small amount is synthesized in dentine by odontoblasts. The synthe-

Received December 19, 1994; accepted June 27, 1995.

Correspondence and reprint requests: Per Magnusson, Bone and Mineral Metabolic Unit, Department of Clinical Chemistry, Linköping University Hospital, S-581 85 Linköping, Sweden.

Supported by grants $92 / 152$ and $94 / 180$ from The County Council of Östergötland and Lions Scholarship for Medical Research. sis is vitamin $\mathrm{K}$-dependent and stimulated by $1,25-(\mathrm{OH})_{2}$ vitamin $\mathrm{D}$. Serum osteocalcin is a specific biochemical marker of bone formation and reflects an altered bone metabolism in patients with metabolic bone disorders characterized by increased or decreased bone turnover (4). Osteocalcin and the bone ALP isoforms appears to reflect different stages in the differentiation of osteoblastic cells leading to formation of calcified extracellular matrix in shape of hydroxyapatite, $\mathrm{Ca}_{10}(\mathrm{OH})_{2}\left(\mathrm{PO}_{4}\right)_{6}(5)$.

Reference values in healthy children and adolescents for total ALP have frequently been reported $(6,7)$. However, reference values in children and adolescents for bone and liver ALP (8-12), and osteocalcin (13-16) are more sparse. Age, sex, race, pubertal, and skeletal maturation are some factors that reffect reference value differences for osteocalcin and the bone ALP isoforms.

We have recently described a new HPLC method which can detect six different ALP isoforms; one bone/intestinal (B/I), two bone (B1 and B2), and three liver ALP isoforms (L1, L2 and L3) (17, 18). This study describes reference values in healthy children and adolescents, age 7-16 y, for osteocalcin and bone and liver ALP isoforms with respect to age, sex, and pubertal stage. 


\section{METHODS}

Subjects. We studied 114 healthy children and adolescents from age 7 to $16 \mathrm{y}, 57$ boys $10.8 \pm 2.4$ y (mean \pm SD), and 57 girls $11.6 \pm 2.5 \mathrm{y}$. They were recruited from a local school population in Linköping, Sweden, and all were reported to be healthy and engaged in normal activities for their age. No one was receiving any drug therapy at the time for blood sampling. Puberty was staged in both boys and girls from I (prepubertal) to $\mathrm{V}$ (adult), according to the Tanner scale (19). Blood samples were taken between 1000 and $1400 \mathrm{~h}$, and serum was stored at $-70^{\circ} \mathrm{C}$ until analyzed.

Laboratory methods. We determined serum bone and liver ALP isoforms with a previously described HPLC method (17, 18). A weak anion-exchange column, SynChropak AP300 (250 $\times 4.6 \mathrm{~mm}$ inside diameter) (SynChrom Inc., Lafayette, IN), was used instead of the referred SynChropak AX300. SynChropak AP300 is a modified SynChropak AX300 which has been optimized for ALP isoform analysis. With SynChropak AP300 the resolution between the bone and liver ALP isoforms is increased. The only difference in the laboratory procedure is that a lower mobile phase $\mathrm{pH}$ has to be used, $\mathrm{pH} 7.6$ instead of $\mathrm{pH}$ 7.8. Reaction $\mathrm{pH}$ in the postcolumn reactor is not altered by the decreased mobile phase $\mathrm{pH}$ because of the low buffer strength, $20 \mathrm{mM}$ Tris acetate, compared with the high buffer strength in the substrate, $0.25 \mathrm{M}$ diethanolamine. A lower mobile phase $\mathrm{pH}$ and two precolumns filled with SynChrosorb AX (SynChrom Inc., Lafayette, IN) were installed to increase the column life and protect the silica-based weak anion exchanger. The precolumns were temperature-controlled at $30^{\circ} \mathrm{C}$ and installed on-line before the solvent mixing module to maintain the same dwell volume as before, $5.4 \mathrm{~mL}$. Details on peak characterization, precision, analytical recovery, linearity data, and detection limit have been published elsewhere (17).

Serum total ALP activity $\left(37^{\circ} \mathrm{C}\right)$ was measured on a Hitachi 717 analyzer (Boehringer Mannheim $\mathrm{GmbH}$, Mannheim, Germany) (20). Osteocalcin was determined by a commercially available RIA kit (INCSTAR, Stillwater, MN) with a double antibody technique (21). The intra- and interassay coefficients of variation at our laboratory for the osteocalcin assay were $3.4 \%$ at $7.4 \mu \mathrm{g} / \mathrm{L}$ and $10.2 \%$ at $5.0 \mu \mathrm{g} / \mathrm{L}$, respectively.

Statistics. All calculations were performed on an Apple Computer, Macintosh, with the StatView ${ }^{\circledR} 4.01$ program (Abacus Concepts Inc., Berkeley, CA, 1993). Nonparametric statistics were used because the distributions were not Gaussian and consent to the Kolmogorov-Smirnov test. Transforming the data to form a Gaussian distribution, e.g. by logarithms, would imply different transforming functions for different analytes. Differences between the age, sex, and pubertal stage groups were studied by the Mann-Whitney test. The KruskalWallis test was used if more than two groups were compared. A $p$ value of 0.05 or less was considered significant.

Ethics. This study was approved by the Ethical Committee of Linköping University Hospital. Informed consent was obtained from the children and their parents before participation in the study.

\section{RESULTS}

We were able to separate and quantify six ALP isoforms in all serum samples from the children and adolescents: one bone/intestinal, two bone and three liver ALP isoforms. A typical chromatographic ALP isoform pattern is presented for a healthy girl, 11 y of age, pubertal stage II, with osteocalcin $11.3 \mu \mathrm{g} / \mathrm{L}$ and B1/B2 0.31 (Fig. 1).

The healthy children and adolescents were grouped into five age groups: $7-8 \mathrm{y}$ of age $(n=15), 9-10 \mathrm{y}(n=33), 11-12 \mathrm{y}$ $(n=26), 13-14$ y $(n=25)$, and $15-16$ y $(n=15)$. The Kruskal-Wallis test showed highly significant variations between the five age groups for: osteocalcin $(p<0.002)$, total $\operatorname{ALP}(p<0.0001), \mathrm{B} / \mathrm{I}(p<0.0012), \mathrm{B} 1(p<0.0001), \mathrm{B} 2(p$ $<0.0004)$, and B1/B2 $(p<0.0025)$. Age- and sex-related percentiles $(25,50$, and 75$)$, minimum and maximum values, are presented for osteocalcin and total ALP (Table 1); B/I, B1, B2 and B1/B2 (Table 2). The divergence between females and males during the years of childhood and adolescence is also presented for total ALP (Fig. 2), B1 (Fig. 3), and B2 (Fig. 4).

Our study subjects were also classified according to the Tanner scale and grouped into three categories of pubertal stages: pubertal stage I $(n=60)$, pubertal stage II-III $(n=27)$, and pubertal stage IV-V $(n=27)$. The Kruskal-Wallis test showed significant variations between the three puberty stage categories for total ALP $(p<0.0015), \mathrm{B} / \mathrm{I}(p<0.03), \mathrm{B} 1(p$ $<0.0015)$, and B2 $(p<0.0045)$. For osteocalcin $(p<0.06)$ and $\mathrm{B} 1 / \mathrm{B} 2(p<0.15)$, variations were considered not significant. Pubertal stage- and sex-related percentiles $(25,50$, and 75), minimum and maximum values are presented for osteocalcin and total ALP (Table 3); B/I, B1, B2, and B1/B2 (Table 4).

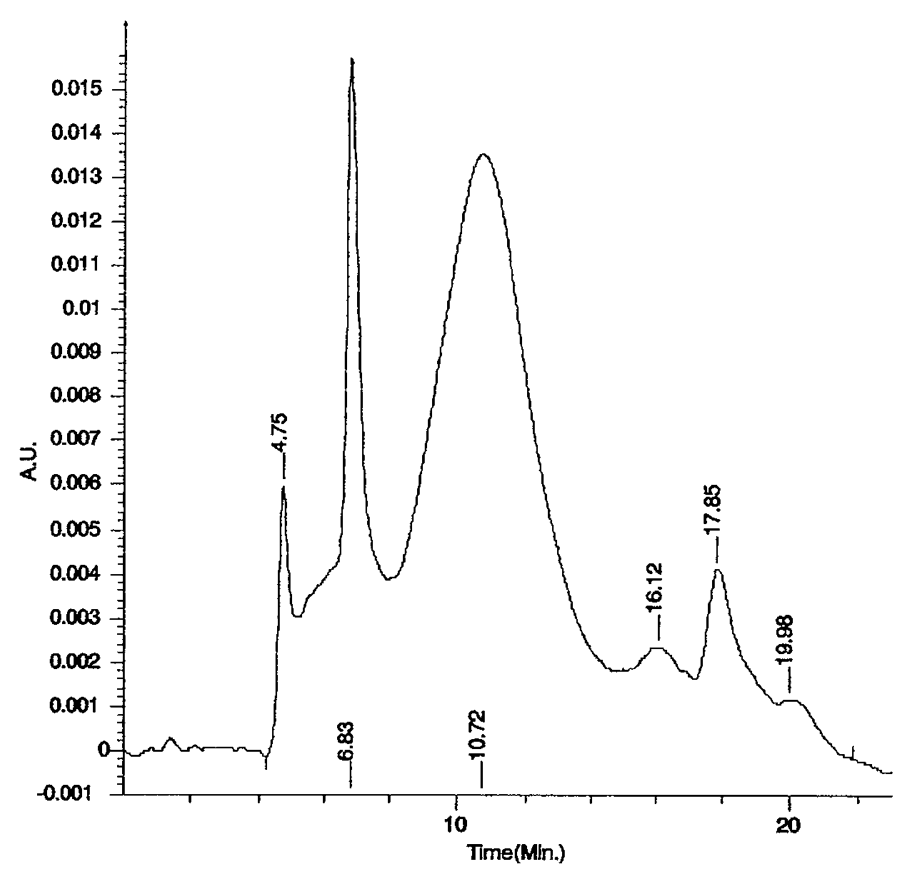

Figure 1. Chromatographic ALP isoform pattern with retention times of serum from a healthy girl, 11 y of age, and total ALP $9.0 \mu \mathrm{kat} / \mathrm{L}$. Peaks, retention times, and activities are, in order of elution: B/I, $4.75 \mathrm{~min}, 0.30$ $\mu \mathrm{kat} / \mathrm{L} ; \mathrm{B} 1,6.83 \mathrm{~min}, 1.75 \mu \mathrm{kat} / \mathrm{L} ; \mathrm{B} 2,10.72 \mathrm{~min}, 5.72 \mu \mathrm{kat} / \mathrm{L} ; \mathrm{L} 1,16.12 \mathrm{~min}$, $0.40 \mu \mathrm{kat} / \mathrm{L} ; \mathrm{L} 2,17.85 \mathrm{~min}, 0.63 \mu \mathrm{kat} / \mathrm{L}$; and L3, $19.98 \mathrm{~min}, 0.20 \mu \mathrm{kat} / \mathrm{L}$. 
Table 1. Age-related values of serum osteocalcin and total ALP

\begin{tabular}{|c|c|c|c|c|c|c|c|c|c|c|c|c|}
\hline \multirow[b]{3}{*}{ Age $(y)$} & \multirow[b]{3}{*}{ Sex } & \multirow[b]{3}{*}{$n$} & \multicolumn{5}{|c|}{ Osteocalcin $(\mu \mathrm{g} / \mathrm{L})$} & \multicolumn{5}{|c|}{ Total ALP $(\mu$ kat/L) } \\
\hline & & & \multicolumn{3}{|c|}{ Percentiles } & \multirow[b]{2}{*}{ Range } & \multirow[b]{2}{*}{$p^{*}$} & \multicolumn{3}{|c|}{ Percentiles } & \multirow[b]{2}{*}{ Range } & \multirow[b]{2}{*}{$p^{*}$} \\
\hline & & & 25 & 50 & 75 & & & 25 & 50 & 75 & & \\
\hline $7-8$ & $F+M$ & 15 & 8.3 & 9.0 & 10.4 & $3.2-12.4$ & NS & 7.3 & 8.4 & 11.3 & $6.2-15.1$ & NS \\
\hline $9-10$ & $F+M$ & 33 & 7.0 & 8.3 & 10.2 & $2.7-12.0$ & NS & 7.9 & 9.4 & 12.3 & $6.4-19.1$ & NS \\
\hline $11-12$ & $F+M$ & 26 & 5.9 & 9.4 & 12.1 & $2.5-16.5$ & NS & 9.4 & 10.8 & 13.1 & $6.7-21.0$ & NS \\
\hline \multirow[t]{2}{*}{$13-14$} & $\mathrm{~F}$ & 15 & 5.9 & 7.4 & 11.2 & $5.8-11.6$ & & 4.6 & 6.1 & 10.6 & $2.0-15.1$ & \\
\hline & $\mathrm{M}$ & 10 & 10.8 & 11.9 & 12.4 & $9.3-13.7$ & $<0.002$ & 11.5 & 14.7 & 15.2 & $6.5-15.7$ & $<0.002$ \\
\hline \multirow[t]{2}{*}{$15-16$} & $\mathrm{~F}$ & 9 & 4.0 & 4.8 & 6.0 & $2.8-6.9$ & & 3.4 & 3.8 & 4.2 & $2.4-4.9$ & \\
\hline & M & 6 & 6.3 & 6.8 & 9.1 & $6.2-11.3$ & $<0.02$ & 7.3 & 8.4 & 10.4 & $7.1-10.8$ & $<0.002$ \\
\hline
\end{tabular}

* Mann-Whitney test between female and male subjects within the age groups.

Table 2. Age-related values of the serum bone ALP isoforms $B / I, B 1, B 2$ and B1/B2 [ratio]

\begin{tabular}{|c|c|c|c|c|c|c|c|c|}
\hline \multirow[b]{2}{*}{ ALP isoform } & \multirow[b]{2}{*}{ Age $(y)$} & \multirow[b]{2}{*}{ Sex } & \multirow[b]{2}{*}{$n$} & \multicolumn{3}{|c|}{ Percentiles } & \multirow[b]{2}{*}{ Range } & \multirow[b]{2}{*}{$p^{*}$} \\
\hline & & & & 25 & 50 & 75 & & \\
\hline \multirow[t]{7}{*}{$\mathrm{B} / \mathrm{I}(\mu \mathrm{kat} / \mathrm{L})$} & $7-8$ & $F+M$ & 15 & 0.25 & 0.30 & 0.35 & $0.16-0.47$ & NS \\
\hline & $9-10$ & $F+M$ & 33 & 0.23 & 0.29 & 0.37 & $0.14-0.62$ & NS \\
\hline & $11-12$ & $F+M$ & 26 & 0.24 & 0.31 & 0.35 & $0.15-0.52$ & NS \\
\hline & $13-14$ & $\mathrm{~F}$ & 15 & 0.16 & 0.25 & 0.30 & $0.04-0.39$ & \\
\hline & & $\mathrm{M}$ & 10 & 0.33 & 0.44 & 0.50 & $0.17-0.52$ & $<0.003$ \\
\hline & $15-16$ & $\mathrm{~F}$ & 9 & 0.12 & 0.15 & 0.17 & $0.05-0.21$ & \\
\hline & & $\mathrm{M}$ & 6 & 0.19 & 0.24 & 0.27 & $0.18-0.30$ & $<0.006$ \\
\hline \multirow[t]{7}{*}{ B1 $(\mu \mathrm{kat} / \mathrm{L})$} & $7-8$ & $F+M$ & 15 & 1.70 & 1.89 & 2.17 & $1.30-3.26$ & NS \\
\hline & $9-10$ & $F+M$ & 33 & 1.53 & 1.99 & 2.44 & $1.01-4.55$ & NS \\
\hline & $11-12$ & $F+M$ & 26 & 1.62 & 2.32 & 2.66 & $1.10-3.83$ & NS \\
\hline & $13-14$ & $\mathrm{~F}$ & 15 & 0.90 & 1.46 & 2.15 & $0.34-2.80$ & \\
\hline & & $\mathrm{M}$ & 10 & 2.27 & 3.10 & 3.25 & $1.14-3.39$ & $<0.002$ \\
\hline & $15-16$ & $\mathrm{~F}$ & 9 & 0.56 & 0.81 & 0.85 & $0.30-0.87$ & \\
\hline & & $\mathrm{M}$ & 6 & 1.57 & 1.61 & 1.64 & $1.33-2.03$ & $<0.002$ \\
\hline \multirow[t]{8}{*}{ B2 ( $\mu \mathrm{kat} / \mathrm{L})$} & $7-8$ & $\mathrm{~F}+\mathrm{M}$ & 15 & 3.85 & 4.56 & 7.20 & $3.23-9.54$ & NS \\
\hline & $9-10$ & $\mathrm{~F}$ & 15 & 5.21 & 7.14 & 8.68 & $3.98-11.39$ & \\
\hline & & $\mathrm{M}$ & 18 & 4.09 & 4.76 & 6.37 & $3.46-8.56$ & $<0.02$ \\
\hline & $11-12$ & $F+M$ & 26 & 6.06 & 6.63 & 8.57 & $4.32-15.13$ & NS \\
\hline & $13-14$ & $\mathrm{~F}$ & 15 & 2.37 & 3.36 & 6.72 & $0.74-10.11$ & \\
\hline & & $\mathrm{M}$ & 10 & 6.54 & 9.17 & 10.01 & $3.88-10.25$ & $<0.002$ \\
\hline & $15-16$ & $\mathrm{~F}$ & 9 & 1.40 & 1.70 & 1.89 & $0.95-2.41$ & \\
\hline & & $\mathrm{M}$ & 6 & 4.16 & 5.19 & 6.51 & $3.83-7.21$ & $<0.002$ \\
\hline \multirow[t]{6}{*}{ B1/B2 [ratio] } & $7-8$ & $F+M$ & 15 & 0.34 & 0.37 & 0.43 & $0.25-0.53$ & NS \\
\hline & $9-10$ & $F+M$ & 33 & 0.31 & 0.35 & 0.38 & $0.26-0.57$ & NS \\
\hline & $11-12$ & $F+M$ & 26 & 0.26 & 0.30 & 0.33 & $0.22-0.51$ & NS \\
\hline & $13-14$ & $F+M$ & 25 & 0.31 & 0.34 & 0.38 & $0.27-0.68$ & NS \\
\hline & $15-16$ & $\mathrm{~F}$ & 9 & 0.36 & 0.43 & 0.48 & $0.21-0.88$ & \\
\hline & & M & 6 & 0.28 & 0.31 & 0.33 & $0.25-0.41$ & $<0.04$ \\
\hline
\end{tabular}

* Mann-Whitney test between female and male subjects within the age groups.

For girls, no significant differences were found with the Mann-Whitney test between the pubertal stage categories I and II-III. For boys, significant differences were found for total ALP $(p<0.05)$ and B2 $(p<0.04)$. However, the MannWhitney test showed highly significant differences between girls in pubertal stage category IV-V compared with the other two categories, I and II-III. IV-V compared with I: osteocalcin, total ALP, B/I, B1, and B2 $(p<0.0001)$, and B1/B2 $(p<$ $0.02)$. IV-V compared with II-III: osteocalcin $(p<0.002)$, total ALP $(p<0.0001), \mathrm{B} / \mathrm{I}(p<0.0005), \mathrm{B} 1(p<0.0001)$, $\mathrm{B} 2(p<0.0002)$, and B1/B2 $(p<0.05)$. For boys, no significant differences were found between the same pubertal stage categories, i.e. IV-V compared with I and IV-V compared with II-III.
The liver ALP isoforms, L1, L2, and L3, are presented together as one group because no significant differences were found between the age, sex, and pubertal stage groups. Reference intervals by 2.5 and 97.5 percentiles for children and adolescents $(n=114)$, age 7-16 y, were L1, 0.28-1.16 $\mu \mathrm{kat} / \mathrm{L}$; L2, 0.41-1.20 $\mu \mathrm{kat} / \mathrm{L} ; \mathrm{L} 3,0.11-0.48 \mu \mathrm{kat} / \mathrm{L}$; and L1 + L2 + L3, 1.08-2.39 $\mu \mathrm{kat} / \mathrm{L}$.

\section{DISCUSSION}

Many analytes vary with age and especially those which reflects changes during puberty, e.g. biochemical markers of bone and mineral metabolism. Infancy through puberty is marked by relatively rapid physiologic changes which often 
Females

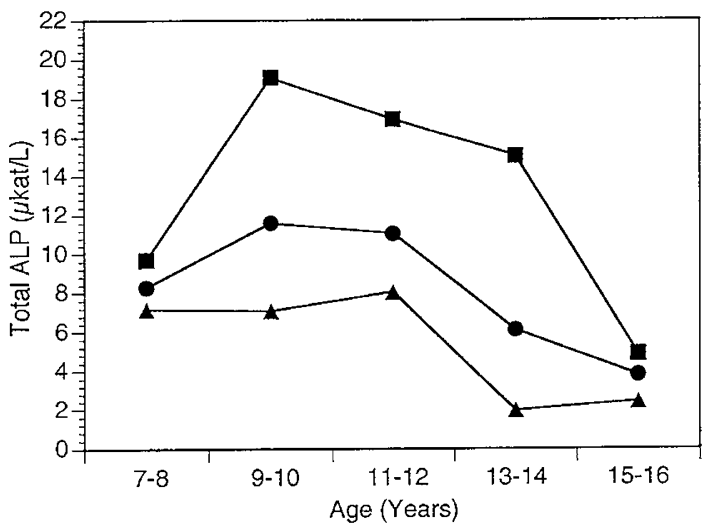

Males

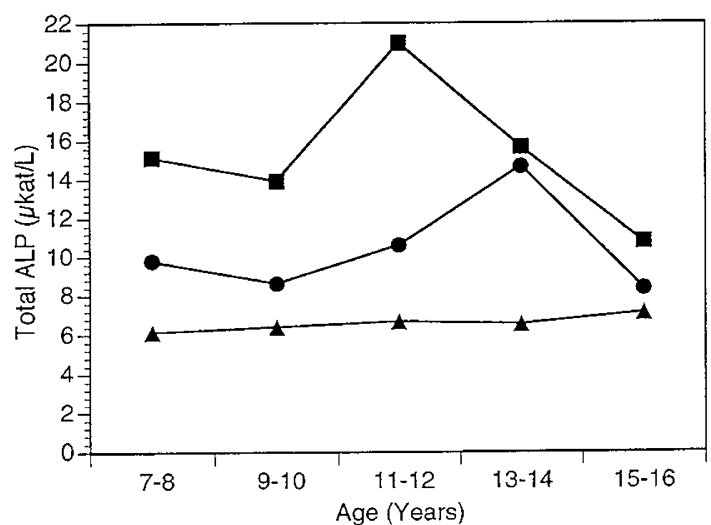

Figure 2. Age distribution of total ALP activities in female and male subjects: maximum values $(\boldsymbol{\square})$, 50th percentiles $(\boldsymbol{\bullet})$, and minimum values $(\boldsymbol{\Delta})$.

cause differing concentrations in biochemical analytes with increasing age. Actually, these differences are de facto expected, and they simply mean that patients' values have to be compared with proper age- and sex-matched reference values.

For the production of accurate reference values it is recommended by the International Federation of Clinical Chemistry, IFCC, to have at least 120 subjects per subgroup (22). However, this is seldom possible because of ethical and practical reasons, and it should be kept in mind that for clinical purposes a small number of values may still serve as a useful guide. In this study we report reference values at percentiles 25,50 , and 75 , in addition to the range, and we preferred not to stress statistical theories presenting reference intervals by 2.5 and 97.5 percentiles because of our small age and pubertal stage groups. The only exceptions are the liver ALP isoforms, $n=$ 114, which are presented as one group.

When comparing different osteocalcin studies, the measured osteocalcin value can differ 10-fold depending on the applied method. Masters et al. (23) compared eight commercially available assay kits for osteocalcin, and they concluded that results cannot be compared between assays even when normalized against healthy subjects. The differences between assays are mostly due to different polyclonal, and monoclonal, antibodies recognizing different epitopes of circulating immunoreactive forms of osteocalcin. To our knowledge, there is only
Females

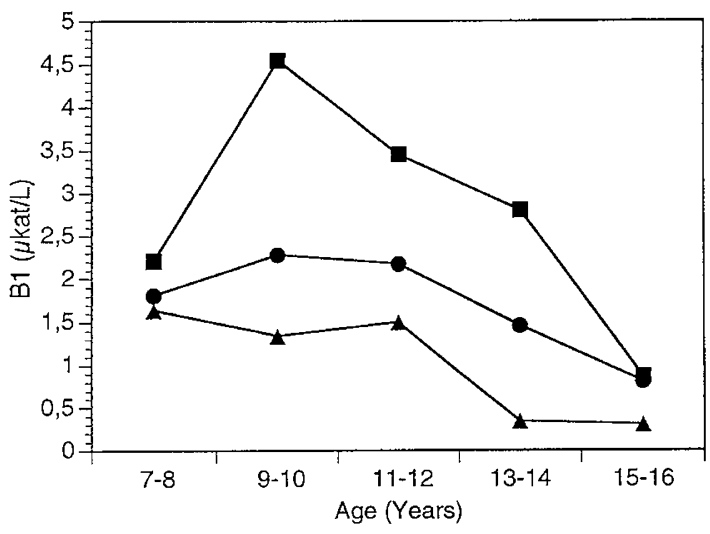

Males

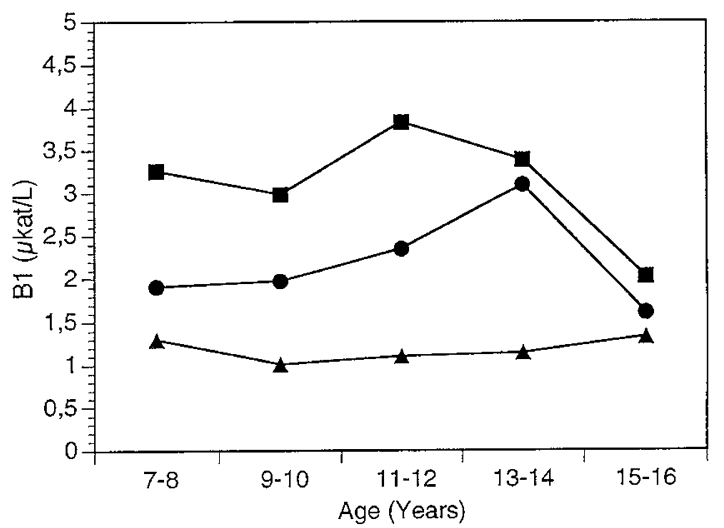

Figure 3. Age distribution of $B 1$ activities in female and male subjects: maximum values $(\boldsymbol{\square})$, 50th percentiles $(\mathbf{O})$, and minimum values $(\mathbf{\Delta})$.

one previous report on reference values for children and adolescents with the same osteocalcin method as ours. Low and Lau (16) investigated 200 healthy Chinese school children and adolescents between the ages of 2 and $20 \mathrm{y}$, however, without classification of pubertal stages. We found a rise in osteocalcin with age, in both sexes, and a decline 2 y earlier for girls than for boys. At the age of 15-16 y for girls, osteocalcin concentrations reached adult levels, in the range $2.8-6.9 \mu \mathrm{g} / \mathrm{L}$. The reported reference values for adults with this osteocalcin method are $1.8-6.6 \mu \mathrm{g} / \mathrm{L}(21)$. Within the pubertal stage group IV-V a highly significant difference was observed between gender, $p<0.0003$.

For adults, the upper reference limit for total ALP is 4.6 $\mu \mathrm{kat} / \mathrm{L}$ in our laboratory. The highest total ALP activity (21.0 $\mu \mathrm{kat} / \mathrm{L}$ ) was observed for a boy, $12 \mathrm{y}$ of age, which is $4-5$-fold more than for healthy adults. Our reference values for total ALP are consistent with several other reports (6-12). For girls we noted the highest values between 9 and $12 \mathrm{y}$ of age, and for boys $2 \mathrm{y}$ later, 11-14 y of age. The activities for the bone ALP isoforms B1 and B2, are up to 10-fold higher for children and adolescents than for adults. This indicates that the measurement of these bone ALP isoforms are more sensitive markers of bone and mineral metabolism than total ALP.

We found the greatest significant differences between the five age groups for total ALP and the bone ALP isoforms, 
Females

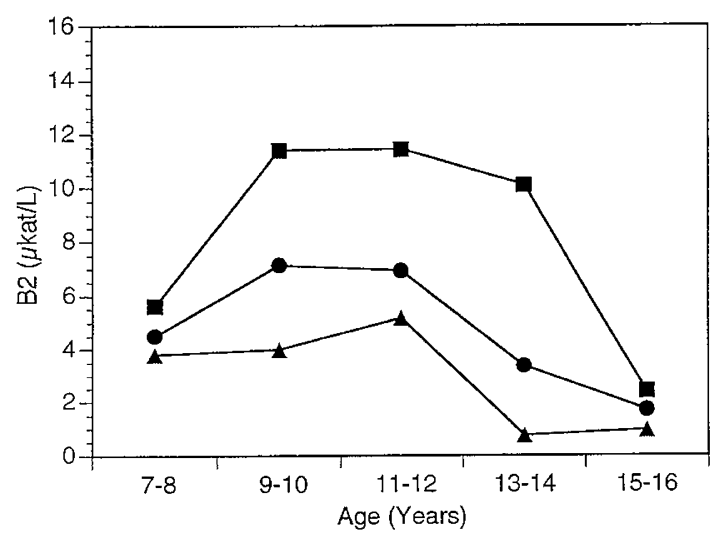

Males

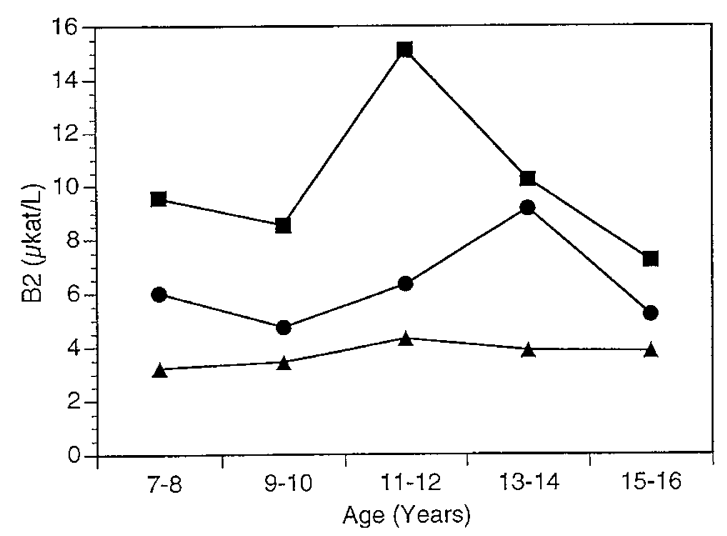

Figure 4. Age distribution of $\mathrm{B} 2$ activities in female and male subjects: maximum values $(\boldsymbol{\Pi})$, 50th percentiles $(\boldsymbol{\bullet})$, and minimum values $(\boldsymbol{\Lambda})$.

which emphasize the necessity of age-matched reference values. We also observed significant differences between gender within the two oldest age groups, 13-14 and 15-16, for total ALP and the bone ALP isoforms. At the age of $14 \mathrm{y}$ some girls already reached adult ALP activities. Within the pubertal stage groups we noted significant differences between gender only in the pubertal stage group IV-V, for the analytes osteocalcin, total ALP, B/1, B1, B2, and B1/B2. The significant differences between the sexes were even more pronounced in the pubertal stage group IV-V than within the oldest age group (15-16 y).

Van Hoof et al. (11) separated ALP isoforms by agarose electrophoresis and were able to separate two bone ALP isoforms in children and adolescents, however, their "bone variant" ALP isoform was not detectable after age $17 \mathrm{y}$ in female subjects and after age $20 \mathrm{y}$ in male subjects. Their "bone variant" ALP isoform probably corresponds to our detected B1 isoform. With this sensitive HPLC method we have not encountered any problems in detecting the bone and liver ALP isoforms, even in serum from adults with hypophosphatasia, at a total ALP $0.5 \mu \mathrm{kat} / \mathrm{L}$ (17).

The significance of the calculated ratio $\mathrm{B} 1 / \mathrm{B} 2$ is not clear. However, we have found values of $\mathrm{B} 1 / \mathrm{B} 2$ below and above the reported reference values during analysis of serum from patients with metabolic bone diseases, in spite of activities within the reference values for the $\mathrm{B} 1$ and $\mathrm{B} 2$ isoforms. For B1/B2, similar observations were found as for osteocalcin, total ALP, $\mathrm{B} / \mathrm{I}, \mathrm{B} 1$, and $\mathrm{B} 2$, i.e. significant differences between gender within the oldest age group (15-16 y), and within the pubertal stage group IV-V. These differences occurred because girls reached higher levels of $\mathrm{B} 1 / \mathrm{B} 2$, hence of a more rapid decline for B2 than for the B1 isoform. This observation might indicate that $\mathrm{B} 2$, to a higher extent than the B1 isoform, represent a more mature expression of osteoblast differentiation during matrix mineralization in growing bone.

The bone ALP isoforms are involved in matrix mineralization and functions as ecto-enzymes attached to cell membranes by a glycosyl-phosphatidylinositol anchor. High activities of ALP have also been reported to be located in matrix vesicles at sites of mineralization (24). As biochemical markers for bone metabolism, bone ALP isoforms may reflect different stages in differentiation of cartilage cells or osteoblast precursors originating from stromal stem cells present in bone marrow. These isoforms could also arise from the fact that human bone is a heterogeneous tissue consisting of trabecular and cortical bone with a wide morphologic variety. Remaining fragments of the cell membrane anchor or different carbohydrate side chains, or both, are other possible reasons why different bone ALP isoforms such as B/I, B1, and B2 are present.

Our reported peak levels for osteocalcin, total ALP and the three bone ALP isoforms, B/I, B1, and B2, follows previously reported peak levels for adolescent growth hormone secretion $(25,26)$. The adolescent growth spurt is very divergent in boys and girls, with girls beginning 2 y earlier and boys having a greater spurt. Monitoring growth in children and adolescents with different growth hormone disorders is an important issue to investigate because both insufficient and excessive amounts of growth hormone have unfavorable metabolic effects. In our point of view, and others $(25,27)$, previously reported biochemical markers of bone are not sensitive enough for reliable predicting individual response to growth hormone treatment. The combined use of several biochemical markers of bone (e.g. osteocalcin, bone ALP isoforms, tartrate-resistant acid phosphatase, cross-linked carboxy-terminal telopeptide of type I collagen, pyridinoline, and deoxypyridinoline cross-links), indicating different aspects of osteoblast and osteoclast proliferation, differentiation, and function, could provide new insights into bone metabolism that have not been possible previously in the individual patient.

The sum of our measured liver ALP isoforms, L1 + L2 + L3, is in agreement with the results of Crofton (12) who used a wheat germ lectin affinity electrophoresis method. However, Crofton could not detect more than one liver ALP isoform in healthy children, and before 6 mo of age, no liver ALP isoforms were detectable. With the described HPLC method it is possible determine the same bone and liver ALP isoforms in serum from infants as from children, adolescents and adults.

We conclude that age- and sex-related reference values are essential for the interpretation of biochemical markers of bone and mineral metabolism, osteocalcin, total ALP, and bone ALP isoforms, B/I, B1, B2, and B1/B2. It is especially important to make distinctions between ages and gender during pubertal stage IV-V, hence girls reach adult levels for osteocalcin, total $\mathrm{ALP}$, and bone ALP isoforms, $\mathrm{B} / \mathrm{A}, \mathrm{B} 1$, and $\mathrm{B} 2$, earlier than 
Table 3. Relation between serum osteocalcin, total ALP, and pubertal stages in female and male subjects

\begin{tabular}{|c|c|c|c|c|c|c|c|c|c|c|c|c|}
\hline \multirow[b]{3}{*}{ Pubertal stage } & \multirow[b]{3}{*}{ Sex } & \multirow[b]{3}{*}{$n$} & \multicolumn{5}{|c|}{ Osteocalcin $(\mu \mathrm{g} / \mathrm{L})$} & \multicolumn{5}{|c|}{ Total ALP $(\mu \mathrm{kat} / \mathrm{L})$} \\
\hline & & & \multicolumn{3}{|c|}{ Percentiles } & \multirow[b]{2}{*}{ Range } & \multirow[b]{2}{*}{$p^{*}$} & \multicolumn{3}{|c|}{ Percentiles } & \multirow[b]{2}{*}{ Range } & \multirow[b]{2}{*}{$p^{*}$} \\
\hline & & & 25 & 50 & 75 & & & 25 & 50 & 75 & & \\
\hline I & $F+M$ & 60 & 7.1 & 8.8 & 10.5 & $2.5-13.5$ & NS & 8.0 & 9.6 & 12.0 & $6.2-19.1$ & NS \\
\hline II-III & $F+M$ & 27 & 6.9 & 9.7 & 11.6 & $5.7-16.5$ & NS & 9.0 & 10.7 & 12.6 & $3.9-21.0$ & NS \\
\hline \multirow[t]{2}{*}{ IV-V } & $\mathrm{F}$ & 14 & 4.5 & 5.9 & 6.5 & $2.8-7.6$ & & 3.5 & 3.9 & 4.7 & $2.0-6.3$ & \\
\hline & M & 13 & 6.8 & 9.8 & 11.8 & $6.2-13.7$ & $<0.0003$ & 8.0 & 10.8 & 14.9 & $6.5-15.7$ & $<0.0001$ \\
\hline
\end{tabular}

* Mann-Whitney test between female and male subjects within the pubertal stage groups.

Table 4. Relation between the serum bone ALP isoforms B/I, B1,B2, BI/B2 [ratio], and pubertal stages in female and male subjects

\begin{tabular}{|c|c|c|c|c|c|c|c|c|}
\hline \multirow[b]{2}{*}{ ALP isoform } & \multirow[b]{2}{*}{ Pubertal stage } & \multirow[b]{2}{*}{ Sex } & \multirow[b]{2}{*}{$n$} & \multicolumn{3}{|c|}{ Percentiles } & \multirow[b]{2}{*}{ Range } & \multirow[b]{2}{*}{$p^{*}$} \\
\hline & & & & 25 & 50 & 75 & & \\
\hline \multirow[t]{4}{*}{$\mathrm{B} / \mathrm{I}(\mu \mathrm{kat} / \mathrm{L})$} & I & $F+M$ & 60 & 0.24 & 0.30 & 0.37 & $0.14-0.62$ & NS \\
\hline & II-III & $F+M$ & 27 & 0.20 & 0.29 & 0.34 & $0.16-0.39$ & NS \\
\hline & IV-V & $\mathrm{F}$ & 14 & 0.11 & 0.15 & 0.21 & $0.04-0.31$ & \\
\hline & & M & 13 & 0.20 & 0.30 & 0.47 & $0.18-0.52$ & $<0.0005$ \\
\hline \multirow[t]{4}{*}{ B1 $(\mu \mathrm{kat} / \mathrm{L})$} & I & $F+M$ & 60 & 1.62 & 1.99 & 2.43 & $1.01-4.55$ & NS \\
\hline & II-III & $F+M$ & 27 & 1.61 & 2.24 & 2.60 & $0.71-3.83$ & NS \\
\hline & IV-V & $\mathrm{F}$ & 14 & 0.59 & 0.83 & 0.88 & $0.30-1.46$ & \\
\hline & & M & 13 & 1.59 & 2.03 & 3.23 & $1.14-3.39$ & $<0.0001$ \\
\hline \multirow[t]{4}{*}{ B2 $(\mu \mathrm{kat} / \mathrm{L})$} & I & $F+M$ & 60 & 4.48 & 5.78 & 7.76 & $3.23-11.43$ & NS \\
\hline & II-III & $F+M$ & 27 & 5.26 & 6.42 & 8.07 & $1.05-15.13$ & NS \\
\hline & IV-V & $\mathrm{F}$ & 14 & 1.41 & 1.75 & 2.63 & $0.74-3.38$ & \\
\hline & & M & 13 & 4.76 & 6.54 & 9.40 & $3.83-10.21$ & $<0.0001$ \\
\hline \multirow[t]{4}{*}{ B1/B2 [ratio] } & I & $\mathrm{F}+\mathrm{M}$ & 60 & 0.30 & 0.34 & 0.38 & $0.25-0.57$ & NS \\
\hline & II-III & $F+M$ & 27 & 0.27 & 0.31 & 0.36 & $0.22-0.68$ & NS \\
\hline & IV-V & $\mathrm{F}$ & 14 & 0.35 & 0.44 & 0.47 & $0.21-0.88$ & \\
\hline & & M & 13 & 0.30 & 0.32 & 0.35 & $0.25-0.41$ & $<0.009$ \\
\hline
\end{tabular}

* Mann-Whitney test between female and male subjects within the pubertal stage groups.

boys. Girls in the oldest age group (15-16 y) and in the pubertal stage group IV-V reached higher levels than boys for the calculated ratio B1/B2 because of a more rapid decline of $\mathrm{B} 2$ compared with $\mathrm{B} 1$. This observation could represent a more mature expression of growing bone for B2 than for the B1 isoform. Serial measurements of these new bone ALP isoforms could provide new insights into bone and mineral metabolism that have not been possible previously. Analysis of the bone and liver ALP isoforms could also clarify the cellular origin of an increased total ALP activity. Nevertheless, morphologic, structural, and physiologic aspects will need further investigation to clarify the clinical significances' of the different bone and liver ALP isoforms.

Acknowledgments. The authors thank Teresa Tkaczuk, Linghem Public School, The City of Linköping, and AnnaEva Ax-Thorn and Inger Larsson, Department of Pediatrics, Linköping University Hospital, for efficient organization of volunteers and sample collection from healthy children and adolescents.

\section{REFERENCES}

1. Fishman WH 1990 Alkaline phosphatase isozymes: recent progress. Clin Biochem 23:99-104

2. Moss DW 1992 Perspectives in alkaline phosphatase research. Clin Chem 38:24862492

3. King JS 1987 Multiple forms of enzymes. Clin Chem 33:1961-1962

4. Power MJ, Fottrell PF 1991 Osteocalcin: diagnostic methods and clinical applications. CRC Crit Rev Clin Lab Sci 28:287-335
5. Stein GS, Lian JB, Owen TA 1990 Relationship of cell growth to the regulation of tissue-specific gene expression during osteoblast differentiation. FASEB J 4:31113123

6. McComb RB, Bowers Jr GN, Posen S 1979 Alkaline Phosphatase. Plenum Press, New York

7. Meites S 1989 Pediatric Clinical Chemistry: Reference (Normal) Values, 3rd Ed American Association for Clinical Chemistry Inc, Washington, DC, pp 203-211

8. Round JM 1973 Plasma calcium, magnesium, phosphorus, and alkaline phosphatase levels in normal British schoolchildren. BMJ 3:137-140

9. Schiele F, Henny J, Hitz J, Petitclerc C, Gueguen R, Siest G 1983 Total bone and liver alkaline phosphatases in plasma: biological variations and reference limits. Clin Chem 29:634-641

10. Stepan JJ, Tesarova A, Havranek T, Jodl J, Formankova J, Pacovsky V 1985 Age and sex dependency of the biochemical indices of bone remodelling. Clin Chim Acta 151:273-283

11. Van Hoof VO, Hoylaerts MF, Geryl H, Van Mullem M, Lepoutre LG, De Broe ME 1990 Age and sex distribution of alkaline phosphatase isoenzymes by agarose electrophoresis. Clin Chem 36:875-878

12. Crofton PM 1992 Wheat-germ lectin affinity electrophoresis for alkaline phosphatase isoforms in children: age-dependent reference ranges and changes in liver and bone disease. Clin Chem 38:663-670

13. Johansen JS, Giwercman A, Hartwell D, Nielsen CT, Price PA, Christiansen C, Skakkebæk NE 1988 Serum bone Gla-protein as a marker of bone growth in children and adolescents: correlation with age, height, serum insulin-like growth factor I, and serum testosterone. J Clin Endocrinol Metab 67:273-278

14. Tarallo P, Henny J, Fournier B, Siest G 1990 Plasma osteocalcin: biological variations and reference limits. Scand J Clin Lab Invest 50:649-655

15. Bouillon R, Vanderschueren D, Van Herck E, Nielsen HK, Bex M, Heyns W, Van Baelen H 1992 Homologous radioimmunoassay of human osteocalcin. Clin Chem 38:2055-2060

16. Low LCK, Lau YL 1992 Serum osteocalcin in normal and short Chinese children. J Paediatr Child Health 28:432-435

17. Magnusson P, Löfman O, Larsson L 1992 Determination of alkaline phosphatase isoenzymes in serum by high-performance liquid chromatography with post-column reaction detection. J Chromatogr 576:79-86

18. Magnusson P, Löfman O, Larsson L 1993 Methodological aspects on separation and reaction conditions of bone and liver alkaline phosphatase isoform analysis by high-performance liquid chromatography. Anal Biochem 211:156-163 
19. Marshall WA, Tanner JM 1986 Puberty. In: Falkner F, Tanner JM (eds) Human Growth: A Comprehensive Treatise. Postnatal Growth Neurobiology, 2nd Ed. Plenum Press, New York, Vol 2, pp 171-209

20. Flood J, Liedtke R, Mattenheimer H, Rothouse L, Trundle D, Vroon D, Whisler $\mathrm{K}$, Collinsworth W 1990 A multicenter evaluation of the Boehringer Mannheim/Hitachi 717 system. Clin Biochem 23:477-488

21. Gundberg CM, Wilson PS, Gallop PM, Parfitt AM 1985 Determination of osteocalcin in human serum: results with two kits compared with those by a well-characterized assay. Clin Chem 31:1720-1723

22. Solberg HE 1987 Approved recommendation (1987) on the theory of reference values. Part 5. Statistical treatment of collected reference values. Determination of reference limits. J Clin Chem Clin Biochem 25:645-656

23. Masters PW, Jones RG, Purves DA, Cooper EH, Cooney JM 1994 Commercial assays for serum osteocalcin give clinically discordant results. Clin Chem 40:358-363
24. Bellows CG, Aubin JE, Heersche JNM 1991 Initiation and progression of mineralization of bone nodules formed in vitro: the role of alkaline phosphatase and organic phosphate. Bone Miner 14:27-40

25. Cara JF 1993 Growth hormone in adolescence. Normal and abnormal. Endocrinol Metab Clin North Am 22:533-552

26. Albertsson-Wikland K, Rosberg S, Karlberg J, Groth T 1994 Analysis of 24-hour growth hormone profiles in healthy boys and girls of normal stature: relation to puberty. J Clin Endocrinol Metab 78:1195-1201

27. Hertel NT, Stoltenberg M, Juul A, Main KM, Müller J, Nielsen CT, Lorenzen I, Skakkebæk NE 1993 Serum concentrations of type I and III procollagen propeptides in healthy children and girls with central precocious puberty during treatment with gonadotropin-releasing hormone analog and cyproterone acetate. J Clin Endocrinol Metab 76:924-927 